\title{
ORGANIZATIONAL CHANGE, SKILL FORMATION, HUMAN \\ CAPITAL MEASUREMENT: EVIDENCE FROM ITALIAN MANUFACTURING FIRMS
}

\author{
Gilberto Antonelli \\ University of Bologna \\ Roberto Antonietti \\ University of Padua \\ Giovanni Guidetti \\ University of Bologna
}

\begin{abstract}
Basing on a job competition approach, in this paper we provide a labour demand-oriented measure of human capital as defined by the amount of specific skills a firm generates through work-based training (WBT) activities.

By merging three rich firm-level datasets, we estimate the impact of a set of variables that are supposed to affect both the propensity to invest in WBT and the intensity of training within the Italian manufacturing industry over the period 2001-2005.The estimates show that the effects of innovation on WBT is higher when the introduction of new technologies is supported by organizational innovations. When looking at the nature of WBT, we investigate the different determinants of the firms' propensity to provide both in-house and outside training. Finally, we estimate training intensity in terms, respectively, of the number of training activities provided, private and total training costs and the share of trainees.
\end{abstract}

Keywords: labour demand, human capital, innovation, organization, work-based training

JEL code: $\mathrm{F} 16, \mathrm{~J} 23, \mathrm{~J} 24$ 


\section{Introduction ${ }^{1}$}

The aim of this paper is to develop a theoretical framework for the measure of human capital. Differently from the standard human capital approach, which is based on labour supply-oriented measures, i.e. schooling, education, experience..., our approach relies on a labour demand perspective ${ }^{2}$ From an empirical view, this approach results into an analysis of the drivers of firm-provided work-based training (WBT), as a measure of human capital.

We address these problems by first developing a conceptual framework in which human capital is acquired not only at school, but primarily on-the-job, and, secondly, by estimating training propensity and intensity on a sample of manufacturing firms operating in Italy over the period 2001-2005.

The structure of the paper is the following. In Section 2, we derive two different ways of measuring human capital by describing two main theories of how labour markets work in generating and allocating working skills. Particular attention is devoted to the jobcompetition model as opposed to standard wage-competition models of the labour market and on how the organization of knowledge within the firm may play a relevant role in affecting both the firms' decision to train and on the amount of training to provide. In this respect, we identify four main drivers of WBT: technological and organizational innovation, internationalization activities, the outsourcing of production activities and, finally, the previous recruitment of new personnel.

Relying on this theoretical framework, in Section 3 we describe the data we use for the following empirical analysis, while in Section 4 we present a set of empirical models for estimating the impact of those variables that are supposed to affect both the propensity to invest in WBT and the intensity of training within the Italian manufacturing industry. In Section 5, we discuss the results of the estimates. In particular, our exercise seems to show that innovation impacts more on WTB than international commitment. In particular, technological and organizational innovations seem to be complementary strategies that positively affect firms' propensity to train. Finally, Section 6 concludes.

\footnotetext{
${ }^{1}$ We are extremely grateful to all the participants at the workshops organized by Giorgio Vittadini and Piergiorgio Lovaglio in the framework of the Lombardy Regional Research Institute (IRER) research project "Human capital in Lombardy". We also acknowledge with thanks Unioncamere and, in particular, Claudio Gagliardi and Francesco Vernaci for their invaluable help in providing and creating the dataset used in this paper. All the usual disclaimers apply.

2 The answer to this question may have strong implications in terms of the evaluation of educational outcomes and quality. For a very preliminary account see Antonelli (2008).
} 


\section{The conceptual framework}

The issue of how to measure human capital from the perspective of labour demand can be tackled by referring at least to two different theories of the labour market ${ }^{3}$.

The first - the wage-competition model - is the dominant one, while the second - the jobcompetition model - is a less frequently adopted framework of analysis, in particular with respect to its implications for the enhancement of the notion and measurement of human capital. In the following two sub-sections we briefly describe how the two models work in allocating skills and in determining the patterns of labour incomes.

\subsection{Two different conceptions of the labour markets}

In standard models of the labour market, the match between labour demand and supply is based on the wage-competition mechanisms. In these models, potential employees compete among each other for a job on the basis of a wage bidding mechanism. When labour supply exceeds labour demand, potential employees underbid the prevailing level of wage, until equilibrium between demand and supply is reached. For each single vacancy, the adjustment process works in the same way and employees' selection occurs on the basis of wage underbidding.

Potential employees are assumed to be homogeneous, so that individual characteristics, such as education, previous working experience, sex, race and the like, are irrelevant. Potential employees differ from one another only on the base of their individual reservation wages. Even when the vacancy is specifically addressed to a welldefined professional profile, recruitment occurs on the basis of a mechanism of wage competition, in which the supply side is defined and limited with respect to the skills attached to the specific professional profile. The market for skills overlaps the market for labour services.

The adjustment process works differently according to Lester Thurow's (1975) job competition model. In this case, the productivity and earnings are determined by job characteristics, so that employers' behaviour and firms' activities become relevant. In order to efficiently match job characteristics with employees' characteristics, employers rank the applicants on the basis of the desired individual and specific traits. These are conceived as proxies of their degree of trainability and capability to adapt to the requirements attached to each specific job, and therefore to their training costs. Definitely, this ranking depends on the specific features of the job and cannot be uniquely defined for all firms. For instance, in certain jobs the previous working experience can be

\footnotetext{
${ }^{3}$ A third view is given by job-matching theories of the labour market. Since we particularly stress the role of labour demand, for simplicity, we focus on the two polar theories, i.e. wage versus job competition. For a review of the different mechanisms underlying all these models see, for instance, Heijke and Muysken (2000).
} 
relevant in defining the individual position in the ranking, whereas, in other job positions, ranking mainly depends on the education or other specific characteristic. However, in any case the employer puts together a queue of applicants which runs from the most favoured applicant to the least preferred one on the base of perceived training costs.

As far as wage setting is concerned, in the job competition model the wage level is exogenously determined with respect to the process of both hiring and individual positioning in the labour queue. Basically, one can point out two different types of drivers in the process of wage setting: external and internal. External drivers refer to factors which affect the labour market as a whole: in particular, centralized bargaining can determine the minimum wage attached to each specific job position. As far as the internal factors are concerned, the structure of each internal labour market, and namely the career paths and the hierarchy of relative wages, defines the wage level within the firms.

In synthesis, we can identify three main differences between the standard model and the job competition model: (i) the wage setting process; (ii) the process of skill formation and development; (iii) the role of labour demand.

In standard models, wages are endogenously determined by the interaction between supply and demand, whereas in the job competition model the process of wage determination is exogenous with respect to employment dynamics.

Regarding skills, in a model of wage competition, the labour market provides the employer with the required skills. Of course, this does not mean that firms do not train their employees. The traditional Beckerian framework (Becker, 1964), based on the distinction between general and specific training, provides the standard interpretation of the process of skill formation and development within firms. Nevertheless, in the wage competition approach, recruitment and skill formation are activities related to two different and distinct processes, as opposed to the job competition approach, in which recruitment occurs on the basis of indicators of trainability.

In this model, skill formation and development are processes inherently linked to firm activities. The match between labour demand and labour supply is always mediated by the expected dynamics of skill formation and development, which adapts the employees' characteristics to the firm's technology and organization of knowledge and work. Skill formation and development allow the establishment of complementary relationships between the techno-organizational design of the firm and the skills of the single employee.

The characteristics of jobs and of labour demand, determined by the organization of knowledge within the firm, do not play any significant role in the standard model. In the job competition model, on the contrary, labour demand plays a key role both in the process of wage setting and in the process of skill formation and development.

When one refers to the organization of knowledge within the firm, three elements have to be emphasised. First of all, the mechanisms underlying internal labour markets have to be carefully taken into account and, especially, the architecture and hierarchy of job 
positions, and the capability to introduce and exploit organizational innovations. Secondly, one should consider technology and the capability of firms to innovate both products and processes. Thirdly, one should consider the entire value chain in which the firm operates, thus looking also at international trade activities and market-oriented strategies.

\subsection{Human capital measurement in a labour demand framework}

In economic theory the concept and measure of human capital has been mostly conceived and developed in the framework of the wage competition model, with special emphasis on labour supply. The reference to the Smith's compensating differentials principle as a keystone of the human capital theory is particularly revealing in this respect.

However, the pragmatic concept has remained rather general and open to a demand side contribution to its formation as the following sentence shows:

"Just as physical capital is created by making changes in materials so as to form tools that facilitate production, human capital is created by changing persons so as to give them skills and capabilities that make them able to act in new ways." (Coleman, 1990, p.304).

The same is true when it is defined as:

"The knowledge, skills, competencies and attributes embodied in individuals that facilitate the creation of personal, social and economic well-being" (OECD, 2001, p.18).

In devoting time and funds to the development of human resources individuals and households, firms and governments carry out forms of activities which are undertaken not only for the sake of present benefits (consumption, availability of required skills), but also for future pecuniary returns (investment) and non pecuniary advantages (risk aversion and precautionary behaviour).

Many activities, like, for instance, schooling, training, experience, mobility, migration, health and sports, influence the stock of human capital the individual, the firm and the society are endowed with and affect the quality of available labour services.

Accordingly, several groups of variables can be identified in trying to describe the nature and scope of human capital. However, the measurement of the human capital can be best conceived in the framework of William Petty's "political arithmetic". This implies the capability to implement a theoretically-based and empirically robust systematic set of accounts in which "number, weight and measure" can be assigned to human resources. Such a complete set has not been yet developed and different measurement frameworks still coexist. ${ }^{4}$

\footnotetext{
${ }^{4}$ See, for instance, Le, Gibson and Oxley (2005), OECD (1998), Stroombergen, Rose and Nana (2002) and Woessmann (2003).
} 
It is well known how relevant has been the notion of capital by Fisher (1906) in making possible the "human capital revolution" and gradually overtaking Marshall's objections to it. In Fisher's analysis, every stock of assets existing at a given point of time which allows a flow of services (payments) over time can be define as capital. The value of each type of capital is given by the present value of the specified stream of payments over time. Time is conceived as an undifferentiated input. ${ }^{6}$

A totally different view was held by Alfred Marshall, according to whom human capital as a pure private good was not a realistic and logically consistent concept. In order to support his influential view, he made reference to the end of the slavery system, to market failures, but especially to the nature of knowledge: non storable, non numerable, non additive, highly idiosyncratic and conceivable as a set of connections based on conjectures.

Even if the notion of human capital was already recognized in the English mercantilist thought and above all in the Smithian vision ${ }^{7}$, and in spite of the attention given to the quality of human resources by other well-known economists ${ }^{8}$, the accomplishment of the human capital theory had to wait till the second half of the 20th century (Blaug, 1972; Antonelli 2003).

The notion of human capital developed by this theory falls in between a Smithian vision of the concept of 'reproducibility' reproducibility, in which no absolute limit exists to productivity increases when human knowledge improves, and a framework dominated by 'absolute scarcity', in which talents are limited by nature. An explanation of the process of human capital formation is provided. And this tends to differentiate it with

\footnotetext{
${ }^{5}$ Gary Becker published in 1964 the first edition of his well known book Human capital. A theoretical and empirical analysis with special reference to education. However, Jacob Mincer published in advance at least two seminal works in human capital theory: A study of personal income distribution, his Doctoral dissertation in 1957, and the article on Investment in human capital and personal income distribution in August 1958. Then he published the article The distribution of labor incomes: A survey in March, 1970, the volume Schooling, experience and earnings in 1974 (NBER edition in 1972). Among his more recent works we can find: The production of human capital and the lifecycles of earnings, published in 1992-93; Human capital: A review, published in 1991-92; Investment in U.S. education and training, published in 1993-94; Economic development, growth of human capital and the dynamics of the wage structure, published in 1994-95; Changes in wage inequality, published in 1995-96. Mincer published his works before Becker, even if he acknowledges his intellectual debt to Becker for the works published after 1957. Moreover, both the authors are greatly indebted to Gregg Lewis and Theodore W. Schultz. In this respect reference can be made also to Psacharopoulos (1987).

${ }^{6}$ This is a definition dealing with a notion of virtual capital, rather than with real or physical capital.

${ }^{7}$ We refer, in particular, to the notion of dexterity in his theory of the division of labour, to his perception of man as a costly and complex machine and to his compensating differentials theory.

${ }^{8}$ Among them Nassau Senior and Arthur Cecil Pigou.
} 
respect to a purely "virtual" notion of human capital that can be found in endogenous growth models as well as in real business cycle models?

Considered from this particular perspective, one of the main outcomes of the human capital theory is the measurement of human capital as a magnitude with the following attributes: expressed in monetary terms; extrapolated from actual income profiles; derived ex-ante; stressing the potential side of human capital.

Human capital is conceived as a monetary stock which is accumulated over the life cycle by the individuals. It is assessed starting from the inspection of the life-time profile of the actual earnings of working employees (extrapolated measure). The amount of stockpiled human capital is determined by the rational behaviour of the individuals aiming at maximising their earnings streams (ex-ante measure). For each individual the life-time profile of the actual earnings depends:

(a) on the life-time profile of capacity or potential earnings (potential nature);

(b) on the amount of human capital employed over time for producing further human capital.

When we come to examine the measurement of human capital in the job competition model, we can suggest three considerations. At a first sight, no monetary measure of human capital is directly designed. Background characteristics can be seen as a vector of variables expressed in real terms and identifying proxies of needed competences by the firms. The vector of job structure and characteristics describes the direct requirements of labour demand, again expressed in real terms, and is the key determinant of every human capital formation. Lovaglio (2009) develops a convincing methodology for the measurement of human capital. In his contribution, human capital is conceived as a non directly observable multidimensional variable which can be measured as a latent variable. In this way both demand and supply factors can be taken into account.

In this respect, we can see that, in the job competition model, the measurement of human capital leads to a magnitude with the following attributes: derived from actual job characteristics; expressed as a vector of variables in real terms; derived ex-post; based on knowledge and skills required and not previously acquired.

Summing up, it should be clear that the job competition approach involves the measurement of human capital on two distinct levels. The first involves the individual characteristics of employees and their endowment of education, previous working experience, functional flexibility, capability to work in team This is a direct measurement of individual human capital, not mediated by the performance of the labour markets since, as observed in the previous section, the process of wage setting is constrained by both the system of centralised bargaining and the binding structure of relative wages fixed in the internal labour market.

\footnotetext{
${ }^{9}$ For a thorough survey on the development of the notion in the history of economic thought, see Folloni, Vittadini, 2009 in this issue of the Journal.
} 
The second level takes account of the stock of human capital measured at a firm level. As previously stated, the creation and development of human capital in firms rests on the techno-organization design, the internal organization of knowledge and the internal dynamics of skill formation and development. This means that the human capital stock depends on four different sets of drivers.

(a) The internal labour markets, the organization of labour and the coordination of tasks among job positions. These factors define the productivity of the single employee, along with the aforementioned individual characteristics. For instance, the employer's strategy to adopt one or more organizational practices, such as task/job rotation, teamwork and so on, define the range and the boundaries of each specific job position.

(b) The technology and the propensity of the firm to innovate. The stock and the type of machineries, capital equipment and in general the technology adopted by the firm constrains the skills which are actually used and their return in the work process.

(c) The dynamics of skill development and the process of adjustment of individual characteristics to the techno-organizational framework. The strategies implemented by the firm for the employees' training affect directly the endowment of human capital available.

(d) The network into which the firm operates, i.e. the position of the firm in the value chain. In particular, the integration or the sub-contracting of production activities to external suppliers may determine the complexity of the production process and the number or quality of tasks to be performed at the workplace, thus affecting the amount of skills required and the amount of training to be provided.

\subsection{Knowledge organization and work-based training}

Given the analysis developed in the previous paragraphs, the organisation of knowledge ${ }^{10}$ in the economic system plays a pivotal role in our interpretative scheme. In the framework of the job competition model, changes linked to the internal organisation of knowledge can be better explained introducing the notion of 'competence pipeline' (Antonelli and Pegoretti, 2008).

Along these lines we may identify two ways through which the division of labour ${ }^{11}$ can be analysed and measured.

Both a disaggregated and an aggregate pipelines can be conceived. The former refers to the cumulative value of the flows of heterogeneous labour services, delivered by each single employee in each period of time over a certain span of her life-cycle. Similarly, the latter can be also conceived as the cumulative value of the flows of heterogeneous labour

${ }^{10}$ That is, making knowledge relevant for economic utilisation (Antonelli and Pegoretti, 2008).

${ }^{11}$ Which is based on knowledge and skills actually used, given the prevailing organization of knowledge. 
services delivered by all the different employees working in each period of time and over a certain span of years within an economic sector, filière or territorial context. A relevant factor for the determination of both pipelines is the amount of firm-provided WBT.

If we examine the outcome of the labour services incorporated in the different vintages of the competence pipeline in both dimensions, an indirect monetary measure of human capital can be derived.

On the one hand, taking into account the disaggregated pipeline, the measure of human capital turns out to be a discounted sum of the differential productivity (differential labour incomes plus profits) generated over time by each individual, plus the opportunity cost of the time spent in other unrewarded activities.

On the other hand, considering the aggregate pipeline, the measure turns out to be a discounted sum of the differential productivity generated by the different workers included in the pipeline, plus the opportunity cost of the time spent in unrewarded activities.

The idea of competence pipeline is able to prop up the measurement of human capital from the labour demand side in that it allows us to think in terms of 'core borings' of the human capital passed through the firm and, to a certain extent, still available according to its past and present needs.

WBT plays a crucial role as a determinant of human capital formation on the demand side. In our definition it includes all the training activities accomplished by the employees and performed after the end of the schooling period under the (total or partial) responsibility of the firm management ${ }^{12}$.

In the following of the paper, we distinguish between: training provided within the firm (in-house training), training provided outside the firm (outside training) and training provided within the firm through the placement of workers side-by-side other colleagues (coaching).

WBT activities are not only a direct way to form and accumulate specific skills, but also a measure of the mismatch between the amount of skills acquired by an individual before entering the labour market and the amount of skills required by the job, or the task, in which she/he is employed.

However, in a job competition framework, skill mismatch may depend on:

(i) a 'pathological disconnection' between the educational system and the economic system in the demand and supply of knowledge and skills (like in the wage competition framework); (ii) a physiological division of labour between the two systems in the process of skill formation.

Human capital investments, in this respect, are treated by the firms much like material capital investments: normally they have to face at least part of their cost in order to

\footnotetext{
${ }^{12}$ It includes, for instance, on-the-job training; off-the-job training; work-based learning; learning by doing; learning by interacting or by using.
} 
reduce the mismatch. The measurement of WBT could be paralleled to the measurement of the schooling years in the human capital model, which is conceived in a labour supply framework. In our case it represents a first step for sketching a more complex model.

\section{Descriptive analysis and dataset creation}

Relying on the theoretical framework described in the previous sections, we now turn to some descriptive and econometric evidence on the factors that affect the training decisions of Italian manufacturing firms.

Our data are drawn from the merge of three distinct datasets: (i) the IX Survey on manufacturing firms (Indagine sulle Imprese Manifatturiere), carried out by Capitalia (formerly Mediocredito Centrale) for the period 2001-2003; (ii) the Excelsior dataset (Sistema Informativo Excelsior), carried out by the Research Office of Italian Chambers of Commerce (Centro Studi Unioncamere) for the period 2004-2006; (iii) the Observatory on the balance sheets of joint-stock companies (Osservatorio sui bilanci delle società di capitale), developed by InfoCamere on behalf of Centro Studi Unioncamere. To our knowledge, this is the first attempt to join the two data sources, so that our empirical analysis can be considered as new in the panorama of the empirical studies on the Italian manufacturing industry.

Table 1. The structure of Capitalia sample by size and geographical area

\begin{tabular}{lclclccc}
\hline \hline Firm size & $\mathbf{\%}$ & Firm size & $\mathbf{\%}$ & Area & $\mathbf{\%}$ & Area & $\mathbf{\%}$ \\
\hline $11-20$ & 22.15 & $11-50$ & 51.69 & North West & 35.91 & North & 66.03 \\
$21-50$ & 29.54 & $51-249$ & 36.93 & North East & 30.12 & Centre & 17.65 \\
$51-250$ & 36.93 & $\geq 250$ & 11.38 & Centre & 17.65 & South & 16.32 \\
$251-499$ & 5.27 & & & South & 16.32 & & \\
$\geq 500$ & 6.11 & & & & & & \\
\hline Total & 100.0 & & 100.0 & & & Total & 100.00
\end{tabular}

The IX Survey on manufacturing firms gathers information on a representative sample of 4.289 manufacturing firms over the period 2001-2003. While firms with more than 500 employees are fully represented, firms employing more than 11 and less than 500 employees are stratified on the base of their size, the region in which they are locate and the sector of economic activity (following ATECO 1991 classification). Table 1 below shows the structure of the Capitalia sample by firm size and geographical area. 
This Survey is of particular importance since it constitutes a rich set of information on firms' characteristics and activities. For the purpose of the paper, we concentrate on sections concerning:

(i) firm size, industrial specialization and the area of localization;

(ii) the labour force composition by occupation;

(iii) technology, as given by firms' investments in new machinery, equipment, product and process innovation, techno-organizational innovation;

(iv) firms' internationalization activities, with particular reference to export, production offshoring and the purchase of business services from abroad;

(v) market-oriented activities, like the outsourcing of goods and services.

The Excelsior data-base is conducted by Unioncamere in cooperation with the Italian Ministry of Labour and Social Welfare and with the European Social Fund, and gathers information on the year-by-year labour demand of a sample of about 100.000 privately-owned firms with more than 1 employee and distributed all over the Italian territory (Centro Studi Unioncamere, 2007).

The survey refers to 27 sectors of economic activity, primarily concentrated within manufacturing, but ranging also over the agricultural and the public sector ${ }^{13}$. Data on labour demand are collected according to two criteria: the ISCO-88 classification of occupations on the one side, and the Excelsior classification on the other, which accounts for the individual worker's level of competence, as defined on the base of the complexity of the tasks operated at the workplace, and the degree of skill specialization, this latter based on the interaction between the knowledge content of tasks and their operating context, i.e. the economic sector.

The Excelsior database is composed by different sections which collect data provided by the local and regional Chambers of Commerce and other administrative archives or from direct interviews to firms conducted in years 2003, 2004 and 2005, with predictions on labour demand for year 2006. In the present context, the sections selected for the empirical analysis concern:

(i) the annual stock of the labour force at the end of each year 2003, 2004 and 2005 and the annual entry and exit flows of labour in 2004, 2005 and 2006 by occupation (managers, executives/clerks, plant operators);

(ii) the volumes of work-based training in 2003, 2004 and 2005, with particular reference to the number of trainees, the costs and the typology of training activities supplied.

Finally, the third data-set provides information on balance-sheet variables relative to joint-stock companies active in the period 2001-2003. The Observatory on the balance sheets is conducted and managed by Unioncamere on the base of the information contained on the national Register of firms, in which all Italian stock companies are

${ }^{13}$ In this work, however, we consider only the manufacturing industry. 
recorded. This database represents a unique source of data since it covers the whole population of Italian stock companies: hence, it allows handling more than 600.000 balance sheets every year and to calculate and analyse the main financial indicators.

After merging the three datasets, we obtain a final sample of 1.545 manufacturing firms with more than 11 employees and active all over the period 2001-2006. The sample is composed by a $20 \%$ of small firms (11-49 employees), a $54 \%$ of medium firms (50-249 employees) and a $26 \%$ of large firms (more than 250 employees), primarily located in the North of Italy (55\%), with respect to a $15 \%$ located in the Centre and a $14 \%$ in the South.

Table 2. Final sample structure by size and geographical area

\begin{tabular}{lccccccccccc}
\hline \multicolumn{1}{c}{ Column \% } & \multicolumn{1}{c}{ Raw \% } \\
\hline & NW & NE & $\begin{array}{c}\text { Cent } \\
\text { re }\end{array}$ & $\begin{array}{c}\text { Sout } \\
\text { h }\end{array}$ & $\begin{array}{c}\text { Tota } \\
\mathbf{l}\end{array}$ & $\begin{array}{c}\mathbf{N} \\
\text { WE }\end{array}$ & $\begin{array}{c}\text { Cent } \\
\text { re }\end{array}$ & $\begin{array}{c}\text { Sou } \\
\text { th }\end{array}$ & $\begin{array}{c}\text { Tota } \\
\text { le }\end{array}$ \\
Small & 110 & 96 & 55 & 45 & 306 & Small & 110 & 96 & 55 & 45 & 306 \\
$\%$ & 18.6 & 18.9 & 23.2 & 21.5 & 19.8 & $\%$ & 35. & 31. & 17.9 & 14.7 & 100. \\
& 1 & 0 & 1 & 3 & 1 & & 95 & 37 & 7 & 1 & 00 \\
Medi & 315 & 288 & 125 & 134 & 862 & Medi & 315 & 288 & 125 & 134 & 862 \\
um & & & & & & um & & & & & \\
$\%$ & 53.3 & 56.6 & 52.7 & 64.1 & 55.7 & $\%$ & 36. & 33. & 14.5 & 15.5 & 100. \\
& 0 & 9 & 4 & 1 & 9 & & 54 & 41 & 0 & 5 & 00 \\
Large & 166 & 124 & 57 & 30 & 377 & Large & 166 & 124 & 57 & 30 & 377 \\
$\%$ & 28.0 & 24.4 & 24.0 & 14.3 & 24.4 & $\%$ & 44. & 32. & 15.1 & 7.96 & 100. \\
& 9 & 1 & 5 & 5 & 0 & & 03 & 89 & 2 & & 00 \\
\hline Total & 591 & 508 & 237 & 209 & 1.54 & Total & 591 & 508 & 237 & 209 & 1.54 \\
& & & & & 5 & & & & & & 5 \\
\% & 100. & 100 & 100. & 100. & 100. & $\%$ & 38. & 32. & 15.3 & 13.5 & 100. \\
& 00 & 00 & 00 & 00 & 00 & & 25 & 88 & 4 & 3 & 00 \\
\hline
\end{tabular}

As far as the composition by industry is concerned, not surprisingly the traditional (46\%) and the specialized-suppliers (31\%) seem to be the most represented sectors, while the science-based $(6 \%)$ is the less populated. Table 2 summarizes the firms' distribution by size and geographical area of localization ${ }^{14}$.

Table 3 compares the 2001 distribution of firms in our Capitalia-ExcelsiorObservatory (CEO) sample with the one emerging from official 2001 Census on manufacturing industry provided by the National Statistical Office (ISTAT, 2001) with respect to firm size and geographical area.

${ }^{14}$ Table A1 in the Appendix, instead, reports the structure of the merged sample by industry. 


\begin{tabular}{lcc} 
Table 3. Sample coverage: CEO and \\
Census data, 2001 \\
\hline Size & ISTAT (\%) & CEO (\%) \\
\hline Small & 87 & 20 \\
Medium & 11 & 54 \\
Large & 2 & 26 \\
Area & & \\
North & 55 & 71 \\
Centre & 21 & 15 \\
South & 24 & 14 \\
\hline Total & 100 & 100 \\
\hline
\end{tabular}

As it can be clearly seen, the main bias in our sample concerns firm size. In particular, while 2001 Census data show that only a $13 \%$ of firms are of medium-large size, in our sample such a percentage rises up to $80 \%$. A similar picture emerges when looking at the macro-area in which firms are located: while the fraction of firms operating in the Centre and North of Italy is about the $75 \%$ of the entire population, in the CEO sample this fraction lies around the $85 \%$.

We identify three possible sources of such a bias. As Tables 1 and 3 show, an initial bias is found in the Capitalia sample, which tends to under-represent the 2001 population of small firms (52\%) and to over-represent the 2001 population of medium-large firms (48\%) with respect to the picture emerging from Census data.

A second cause is the fact that both within the Capitalia and within the Excelsior datasets, small firms are selected by sampling, while the population of large firms interviewed represents the universe. The implication is that, when merging the two data-sets, the probability to exclude small firms is higher than the probability to exclude large firms.

Finally, the third source is given by the higher mortality rate of small firms with respect to large firms. When dealing with longitudinal data, the probability for a small firm to survive is generally lower than the one of a large firm, as recent empirical studies on firms demographic evolution and on the determinants of firms survival rate clearly show (Agarval and Audretsch, 2001; ICE-ISTAT, 2007). Moreover, smaller firms are also more subject to merges or take-overs, i.e. activities that tend to change their average dimension towards larger sizes.

However, our merged sample is representative of those firms that, over the period under investigation, constitute the 'backbone' of the Italian manufacturing industry, particularly when referring to activities like technological and organizational innovation, $R \& D$ and international trade. In other words, the sample is representative of those industries that show the highest capacity to introduce and manage innovation processes as well as to penetrate foreign markets. 
Table 4. Firms and employment distribution in Italian manufacturing (\%)

\begin{tabular}{lcccccc}
\hline & \multicolumn{3}{c}{ CIS3 (1998-2000) } & \multicolumn{3}{c}{ CEO (2001-2003) } \\
\hline Typology of firm & Small & Medium & Large & Small & Medium & Large \\
Innovative & 37 & 60 & 78 & 56 & 74 & 84 \\
Non innovative & 63 & 40 & 22 & 44 & 26 & 16 \\
Total & 100 & 100 & 100 & 100 & 100 & 100 \\
R\&D & 31 & 61 & 79 & 34 & 58 & 60 \\
NO R\&D & 69 & 39 & 21 & 66 & 42 & 40 \\
Total & 100 & 100 & 100 & 100 & 100 & 100 \\
New equipment & 67 & 71 & 79 & 85 & 90 & 96 \\
No new equipment & 33 & 29 & 21 & 15 & 10 & 4 \\
\hline Total & 100 & 100 & 100 & 100 & 100 & 100 \\
\hline Typology of firm & \multicolumn{7}{c}{ Employment share } \\
Innovative & 41 & 62 & 83 & 58 & 75 & 60 \\
Non innovative & 59 & 38 & 17 & 42 & 25 & 40 \\
\hline Total & 100 & 100 & 100 & 100 & 100 & 100 \\
\hline Source: Table IT.2B, p. 163 (European Commission, CIS3) and Authors' elaboration on \\
CEO dataset.
\end{tabular}

In this respect, data from the Community Innovation Survey 3 (European Commission, 2001), for instance, show that medium and large firms, although less numerous in absolute terms, constitute the highest fraction of firms, respectively: introducing product and/or process innovations; introducing successful innovations; employing more workers in innovation activities; gaining the highest profits from innovations. In this context, Table 4 compares the distribution of firms in the CIS 3 (in 1998-2000) and in the CEO sample (2001-2003) by the type of innovation-related activity. Although some slight discrepancies still persist, mainly due to the different time span considered, the picture described in the CEO sample seems to be in line with the one described in the CIS3. The emerging result is that medium and large firms in 2001-2003 not only invest more in $R \& D$ and innovation activities, but, in these sectors, tend to employ more labour than smaller firms.

A similar picture can be derived when looking at the volumes of international trade of Italian manufacturing firms. Data from Capitalia (2005) and ICE-ISTAT (2007), for instance, show that the weight of medium and large firms in foreign expansion activities is not only bigger than the one of small firms, but it is also increasing over time. This occurs not only when looking at exports data, but also when looking at the trends in offshoring, foreign direct investments and foreign-controlled firms ${ }^{15}$.

${ }^{15}$ Tables A2 and A3 in Appendix A, for instance, show respectively some international data on the distribution of firms that export goods and services in the period 2002-2005 and some data on the distribution of the value of exports within Italian manufacturing. 


\section{Descriptive analysis: the characteristics of labour demand}

In this section we provide some descriptive statistics concerning both the main characteristics of labour demand by type of education (Table 5) and experience required (Table 6) within Italian manufacturing and the characteristics of the training activities (Table 7) over the period 2004-2005.

Table 5. Labour demand by firm size and level of education required

\begin{tabular}{llccc}
\hline Size & Education required & N. & \% & Cumulated \% \\
\hline Large & Primary education & 191 & 12,5 & 12,5 \\
& Regional vocational training & 36 & 2,3 & 14,8 \\
& Vocational training & 151 & 9,8 & 24,7 \\
& Secondary school & 565 & 36,9 & 61,5 \\
& College degree & 590 & 38,5 & 100,0 \\
& Total & 1533 & 100,0 & \\
Medium & Primary education & 298 & 22,2 & 22,2 \\
& Regional vocational training & 65 & 4,9 & 27,1 \\
& Vocational training & 193 & 14,4 & 41,5 \\
& Secondary school & 558 & 41,6 & 83,1 \\
& College degree & 226 & 16,9 & 100,0 \\
& Total & 1340 & 100,0 & \\
& Primary education & 53 & 34,9 & 34,9 \\
& Regional vocational training & 9 & 5,9 & 40,8 \\
& Vocational training & 25 & 16,4 & 57,2 \\
& Secondary school & 55 & 36,2 & 93,4 \\
& College degree & 10 & 6,6 & 100,0 \\
\hline & Total & 152 & 100,0 & \\
\hline
\end{tabular}

With respect to the former aspect, as Table 5 shows, a positive correlation between education required and firm size emerges neatly, especially if one focuses on demand for graduates and for employees with only primary education. While labour demand for large firms refers to a $38.5 \%$ of individuals with a college degree, medium-sized firms are primarily interested in workers with a secondary school degree (41.6\%), leaving only a $16.9 \%$ of their recruitment to people with a college degree. The picture is even more emphasized for small firms, the interest of which is more heavily concentrated on secondary school leavers $(36.2 \%)$ or vocational training programs leavers $(12.5 \%)$. 
With respect to previously acquired experience, Table 6 shows that, in general terms, the need for experience increases with firm size: the demand for totally inexperienced individuals is much higher for small firms (33.6\%) than for large firms (19.5\%). Going through the type of experience required, large firms prefer to hire employees with totally specific $(33,9 \%)$ and sector-specific experience $(31,7 \%)$, whereas small and medium size firms are more willing to employ employees with sector-specific experience (respectively $38 \%$ and $38,2 \%)$.

Table 6. Labour demand by firm size and type of experience

\begin{tabular}{llccc}
\hline Size & Experience & N. & $\mathbf{\%}$ & Cumulated \% \\
\hline Large & Fully specific & 519 & 33,9 & 33,9 \\
& Sector-specific & 486 & 31,7 & 65,6 \\
& General & 229 & 14,9 & 80,5 \\
& No experience & 299 & 19,5 & 100,0 \\
& Total & $\mathbf{1 5 3 3}$ & $\mathbf{1 0 0 , 0}$ & \\
Medium & Fully specific & 324 & 24,2 & 24,2 \\
& Sector-specific & 509 & 38,0 & 62,2 \\
& General & 173 & 12,9 & 75,1 \\
& No experience & 334 & 24,9 & 100,0 \\
& Total & $\mathbf{1 3 4 0}$ & $\mathbf{1 0 0 , 0}$ & \\
Small & Fully specific & 24 & 15,8 & 15,8 \\
& Sector-specific & 58 & 38,2 & 53,9 \\
& General & 19 & 12,5 & 66,4 \\
& No experience & 51 & 33,6 & 100,0 \\
& Total & $\mathbf{1 5 2}$ & $\mathbf{1 0 0 , 0}$ & \\
\hline
\end{tabular}

Finally, when looking at work-based training by size an over time, Table 7 shows that large firms have a higher propensity to invest in training programmes $(79,9 \%)$ with respect to the medium $(43,2 \%)$ and the small ones $(26,5 \%)$, and that this trend is increasing over time for medium and large firms while decreasing for small ones. 
Table 7. Firms providing training to their employees by size

\begin{tabular}{llcccc}
\hline & & \multicolumn{2}{c}{$\mathbf{2 0 0 4}$} & \multicolumn{2}{c}{$\mathbf{2 0 0 5}$} \\
\hline Size & Training & $\mathbf{N .}$ & $\mathbf{\%}$ & $\mathbf{N .}$ & $\mathbf{\%}$ \\
Large & Yes & 297 & 78.78 & 298 & 79.05 \\
& No & 80 & 21.22 & 79 & 20.95 \\
& Total & 377 & 100.0 & 377 & 100.0 \\
Medium & Yes & 364 & 42.23 & 375 & 43.50 \\
& No & 498 & 57.77 & 487 & 56.50 \\
\multirow{5}{*}{ Small } & Total & 862 & 100.0 & 862 & 100,0 \\
& Yes & 81 & 26.47 & 76 & 26,5 \\
& No & 225 & 73.53 & 230 & 73,5 \\
Total sample & Total & 306 & 100.0 & 306 & 100,0 \\
& Yes & 742 & 48.03 & 749 & 48.48 \\
& No & 803 & 51.97 & 796 & 51.52 \\
\hline & Total & $\mathbf{1 . 5 4 5}$ & $\mathbf{1 0 0 . 0}$ & $\mathbf{1 . 5 4 5}$ & $\mathbf{1 0 0 . 0}$ \\
\hline
\end{tabular}

Figure 1. Mean share of trainees by firm size (2004 and 2005)

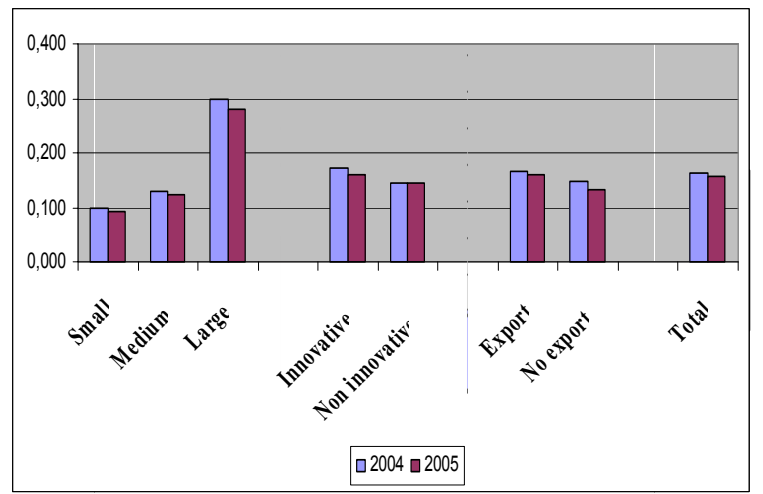

Next to the propensity to train, we provide also some preliminary evidence on the intensity of training in Italian manufacturing. In particular, we focus on the average share of trainees and on average training costs per trainee. In Figure 1, we present some graphical statistics for the average share of trainees by firm size, propensity to innovate and propensity to export. As expected, large firms train a higher fraction of their 
workforce both in 2004 and in 2005 with respect to small and medium firms. In addition, innovative and export-oriented firms tend to train a higher fraction of their workforce than non innovative and domestic competitors. Finally, one should note that these trends are slightly declining over time, as the share of trainees passes from an average of $16.3 \%$ in 2004 to an average of $15.6 \%$ in 2005 .

\section{Figure 2. Average training cost per trained employee, 2004 and 2005}

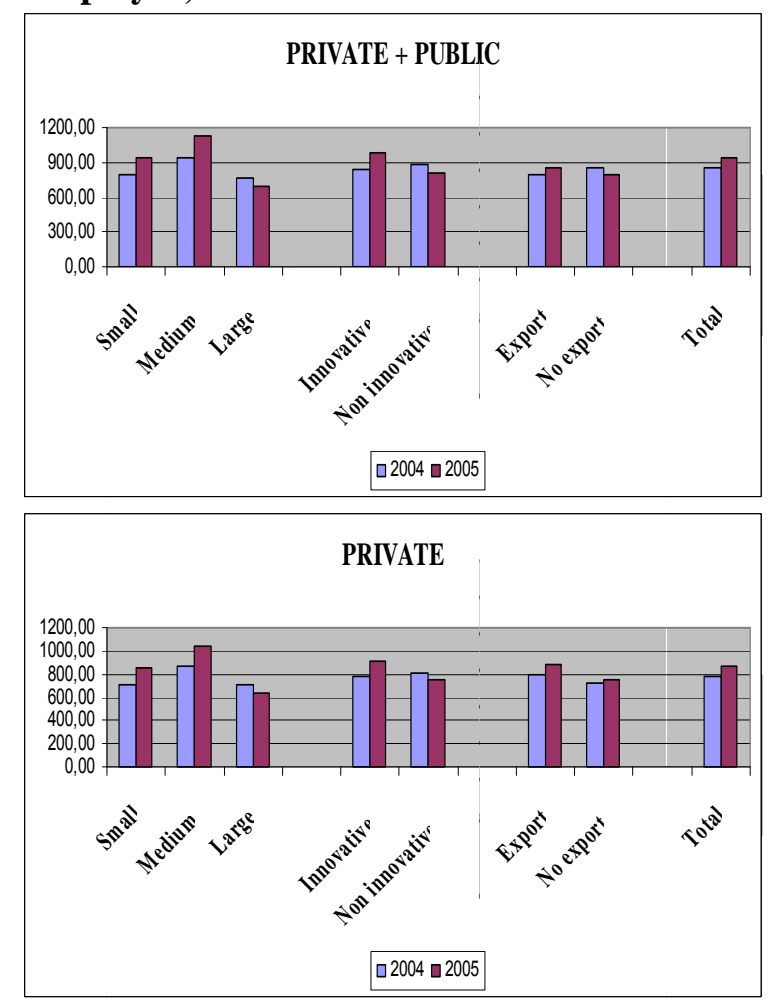

Mean values refer to the sub-sample of firms providing training in 2004 and 2005 respectively.

Figure 2, instead, shows the trends in 2004 and 2005 average nominal training costs. In particular, the left box refers to total (nominal) training costs, while the right box specifically refers to entirely private, firm-provided, (nominal) expenditures. Differently from before, medium-sized firms tend to spend more in average than small and large competitors. Innovative and export-oriented firms spend less than non-innovative and 
domestic counterparts only in 2004, the opposite being true in 2005. Finally, we note that total average training costs are increasing over time, particularly in terms of private expenditures ${ }^{16}$.

Table 9. Typologies of training by firm size (\%)

\begin{tabular}{lcccccc}
\hline \multicolumn{5}{c}{$\mathbf{2 0 0 4}$} & \multicolumn{3}{c}{$\mathbf{2 0 0 5}$} \\
\hline Size & In-house & Outside & Coaching & In-house & Outside & Coaching \\
Large & 92.59 & 82.49 & 80.47 & 92.28 & 75.84 & 77.18 \\
Medium & 75.27 & 70.60 & 35.16 & 75.20 & 66.40 & 32.27 \\
Small & 51.85 & 69.14 & 9.88 & 59.21 & 63.16 & 11.84 \\
\hline Total & $\mathbf{7 9 . 6 5}$ & $\mathbf{7 5 . 2 0}$ & $\mathbf{5 0 . 5 4}$ & $\mathbf{8 0 . 3 7}$ & $\mathbf{6 9 . 8 3}$ & $\mathbf{4 8 . 0 6}$ \\
\hline \multicolumn{7}{c}{ Percentages refer to the sub-sample of firms providing training in 2004 and 2005 }
\end{tabular}

Finally, our dataset allows also identifying three different typologies of work-based training: (a) in-house training; (b) training outside the firm; (c) coaching (affiancamento). As Table 9 shows, in-house is the most preferred form of training by medium and large firms, while small firms prefer to train workers outside. Interestingly, large firms are also highly involved in providing training through coaching, while small and medium firms are more willing to provide formal types of training, although coaching is increasing from 2004 to 2005 for small firms only.

\section{Estimating an empirical model}

The main aim of the following analysis is to start estimating the patterns of skill formation in a labour demand setting. In particular, we assume that, next to standard ways to measure human capital from a labour supply perspective - primarily based on education and training acquired by individuals - an alternative measure of human capital is given by the amount of WBT firms provide to their workforce. WBT activities are not only a direct way to form and accumulate specific skills, but also a measure of the mismatch between the amount of skills acquired by an individual before entering the labour market and the amount of skills required by the job, or the task, in which he/she is employed.

Measuring human capital from the labour-demand side is not an easy task. Apart from a chronic lack of firm-level data on training activities, we face also the difficulty of measuring the level and quality of the competencies required by firms, as well as the skill

16 The variance of training expenditures is also increasing over time: standard errors for total average training expenditures is 902.27 in 2004 and 1430.06 in 2005, while for private training expenditures it passes from a value of 875.94 in 2004 to a value of 1415.81 in 2005. 
content of tasks. However, a first step in this direction may consist in offering some measures of training intensity and in investigating which factors, among firms' strategies, activities and structural characteristics, do offer the most relevant contribution in driving and shaping the training decisions of firms.

Using the CEO data-base, we will analyse how firms' characteristics and actions in the period 2001-2003 did affect their investments in training in 2004.

Keeping in mind the conceptual framework presented in Section 2, we now turn the attention on the explanatory variables that, according to us and to the (scanty) related literature (Baldwin and Johnson, 1995; Baldwin, Gray and Johnson, 1995; Antonietti, 2007; Bassanini et al., 2007; Hollenstein and Stucki, 2008) may play a role in affecting firms' decision to train workers. In particular, we focus on activities like technological and organizational change, internationalization and market-oriented activities like outsourcing.

In the basic structure of the empirical model we are going to estimate, the dependent variable is given by the choice to provide training in 2004 (in general terms, or by type of training or by occupation) As far as the explanatory variables are concerned, we put firm size, industrial specialization, previous recruitment of personnel, technological and organizational innovation, outsourcing, and foreign expansion. All these variables are measured in the previous three years (2001-2003),

With respect to the factors that affect our human capital variable, i.e. WBT propensity and intensity, we particularly emphasise two aspects that characterize the 'competence pipeline' described in Section 2: the role played by the recruitment of new personnel and the role played by organizational change, this latter conceived both in terms of innovative activities and in terms of internationalization commitment. In this respect, the notion of 'competence pipeline' is of particular importance since it provides a useful theoretical support for the measurement of human capital from a labour demand perspective in that it allows us to think in terms of 'core borings' of the human capital passed through the firm and, to a certain extent, still available according to its past and present needs.

\subsection{Estimates based on the logit model}

In estimating our empirical model we follow a two stage approach. In the first stage we are interested in estimating the firms' propensity to invest in training in 2004, both in general terms and as referred to the different occupations and to the different typologies of training provided. Since all the dependent variables are the binary choice concerning the choice to provide WBT, we rely on a logit specification in order to estimate our model.

Our first empirical model is based on a standard logit specification of the type (Wooldridge, 1999; Greene, 2002):

$$
\operatorname{Pr}\left(W B T_{i}=1 \mid \mathbf{x}_{\mathbf{i}}=x_{i}\right)=\Lambda\left(\mathbf{x}^{\prime} \beta\right)=\exp \left(\mathbf{x}^{\prime} \beta\right) /\left[1+\exp \left(\mathbf{x}^{\prime} \beta\right)\right]
$$


where $\Lambda$ is the cumulative standard logistic distribution function of the random variable WBT. Through this equation we estimate the impact of a vector $\mathbf{x}$ of regressors on the probability for a firm $i$ to invest in training $\left(W B T_{i}=1\right)$ in the year 2004 .

Since our dataset allows also distinguishing the destination of training activities by occupation, we also specify our dependent variable in terms of WBT for the top and middle management $($ WBTM $)$ and WBT for plant operators $(W B T O)^{17}$.

In addition, we also define three dummies measuring the three different typologies of training: WBT in-house for firms providing in-house training, WBT outside for firms providing training outside the firm, WBT coaching for firms training workers by placing them side-by-side other colleagues. Table 10 summarizes the three sets of dependent variables that we consider for our logit estimates.

Table 10. Training 2004 by occupation and typology (\% in brackets)

\begin{tabular}{lcc}
\hline WBT & Managers & Plant operators \\
\hline In-house & $560(94.75)^{*}$ & $499(84.43)$ \\
Outside & $525(94.09)$ & $448(80.29)$ \\
Coaching & $357(78.98)$ & $335(74.12)$ \\
\hline Total WBT & $685(44.34)$ & $591(38.25)$ \\
\hline
\end{tabular}

(*) Percentages in brackets refer to the total amount of firms providing each type of training respectively. In the first cell, $94.75 \%$ of firms providing in-house training involve managers, while the $84.43 \%$ involve plant operators. This means that in-house training is almost common for both managers and machine operators.

As independent variables, we identify two sets of regressors: (i) controls and (ii) explanatory variables of organizational change that are supposed to underlie the training decisions of firms, as suggested by the theoretical framework and the economic literature. All these independent variables refer to the period 2001-2003 in order to avoid a priori problems of simultaneity with the training decision variable.

As controls we include: (i) four geographic area dummies (North West, North East, Centre and South); (ii) firm size as given by 2001-2003 average employment (natural $\log$ ); iii) fourteen industry dummies, according to the industry to which the firm belongs; (iv) a variable measuring the capital intensity of production, as given by deflated net technical assets per employee, in natural $\log (\log K / L)$; (v) a variable reflecting the skill

${ }^{17}$ Due to the presence of a high number of zeros $(80 \%)$ in the dummy variable for training top managers, we aggregate top and middle managers in one variable ( $56 \%$ of zeros). 
composition of the labour force, i.e. the $\log$ share of white collars $\left(\log _{-} W C / L\right)^{18}$; (vi) two dummy variables capturing, respectively, the acquisition of public funds for training in year 2003 (public) and the use of private funds for financing training in 2003 (private) ${ }^{19}$.

As explanatory variables, we focus on firms' propensity to hire new workers in year 2003 and on three activities that are supposed to capture organizational change: innovation, internationalization commitment and outsourcing.

The recruitment of new personnel is measured by a dummy variable (hire 2003) which equals 1 if the firm hires new workers in the period 2001-2003 and 0 if not. Innovation is captured by three dummies concerning firm's investments in new machinery and equipment (investments), the introduction of new product and/or processes (inno_tech) and the introduction of organizational innovations due to the introduction of new products and/or new processes (inno_org).

Firms' internationalization is measured through three dummies: one equal to 1 if the firm engaged in exporting activities over the period 2001-2003 (export) and 0 otherwise, another equal to 1 if the firm moved production abroad (offshoring) and the third equal to 1 if the firm purchased service activities from abroad during 2001-2003 (services).

Finally, outsourcing is measured by a dummy variable (outsourcing) equal to 1 if the firm contracted out activities that were previously integrated and 0 otherwise.

\subsection{Ordered logit estimates on training intensity}

After focussing on the propensity for a firm to invest in WBT, we estimate training intensity, as captured by the cumulative combination of different typologies of training programmes: in-house, outside and coaching.

We measure training composition by defining an ordered index (WTI) assuming a value equal to 0 for firms which do not supply any work-based training programmes, 1 for firms supplying only in-house training programmes; 2 for the firms providing both inhouse and outside training; 3 for the firms providing all the three forms of training programmes.

The basic idea is that the amount of training supplied can be thought as a proxy of the mismatch between the skills acquired by workers within the external educational and training sub-system and the skill required within the firm. In addition, WTI is a direct way for the firms to create or update technology-specific competences that are generally made obsolete by technological or organizational change.

Table 11 shows the various forms of training modes detected and the relative frequency distributions.

\footnotetext{
${ }^{18}$ The Appendix provides summary statistics and a more detailed definition on these variables.

${ }^{19} \mathrm{We}$ also have information on the amount of public and private funds used for financing training in 2003, but, due to the high number of zeros, we are not able to provide reliable estimates.
} 
Table 11. Firms distribution among four typologies

of work-based training

\begin{tabular}{cccc}
\hline Types of WBT & N. & \% & Cumulative \% \\
\hline 0 & 954 & 61.75 & 61.75 \\
1 & 184 & 11.91 & 73.66 \\
2 & 150 & 9.71 & 83.37 \\
3 & 257 & 16.63 & 100.0 \\
\hline Total & 1.545 & 100.00 & \\
\hline
\end{tabular}

Since our training index is an ordered categorical variable, ranging from 0 to 3 , we use an ordered logit model as more appropriate for explaining variations in the training composition than a linear regression model. Whereas in the latter, a firm with a training index of 2 would be twice training intensive as one with an index of 1 , in the ordered logit model no such an assumption of cardinality is made: a training index of 2 simply indicates more training patterns than training index of 1 .

The basic idea underlying the model is the existence of a latent continuous variable, $W T I^{*}$, that indicates the degree of training intensity of a firm. The relationship between this latent variable and the set of explanatory variables is the following:

$$
W T I_{i}^{*}=\mathbf{x}_{\mathbf{i}} \beta+\varepsilon_{i}, \text { with } \varepsilon_{i} \approx N \quad 0,1
$$

where $\mathbf{x}_{i}$ is the vector of regressors influencing the level of $W T I$ and $\varepsilon_{i}$ is the random error component drawn from a standardized normal distribution. Although $W B I$ is not observed, the integer index $W T I$ is observed and related to $W T I^{*}$ by the following relationship:

$$
\begin{aligned}
& W T I_{i}=0 \text { if } W_{T I}^{*} * 0, \\
& W T I_{i}=1 \text { if } W T I_{i} *<\delta_{1}, \\
& W T I_{i}=2 \text { if } W T I_{i}^{*}<\delta_{2}, \\
& W T I_{i}=3 \text { if } W T I_{i} *<\delta_{3},
\end{aligned}
$$

in which $\delta_{i}$ are the unobserved free threshold parameters (cut points) which define the boundaries between the different levels of WTI. Given the relationship between WTI and $W T I^{*}$ and the distribution of the error term, we can write the probability of observing a firm as having a zero value of $W T I$ as:

$$
\operatorname{Pr}(W T I=0)=\operatorname{Pr}\left(W T I^{*} \leq 0\right)=\operatorname{Pr}\left(\varepsilon \geq-\mathbf{x}^{\prime} \beta\right)=\Lambda\left(-\mathbf{x}^{\prime} \beta\right)
$$


where $\Lambda(\bullet)$ is the standard logistic distribution function. Similarly, we can specify the other probabilities as:

$$
\begin{aligned}
& \operatorname{Pr}(W T I=1)=\operatorname{Pr}\left(W T I^{*} \leq \delta_{1}\right)=\Lambda\left(\delta_{1}-\mathbf{x}\right)-\Lambda(-\mathbf{x} \beta) \\
& \operatorname{Pr}(W T I=2)=\operatorname{Pr}\left(W T I^{*} \leq \delta_{2}\right)=\Lambda\left(\delta_{2}-\mathbf{x} \beta\right)-\Lambda\left(\delta_{1}-\mathbf{x} \beta\right) \\
& \operatorname{Pr}(W T I=3)=\operatorname{Pr}\left(W T I^{*} \leq \delta_{3}\right)=1-\Lambda\left(\delta_{2}-\mathbf{x} \beta\right)
\end{aligned}
$$

Estimates are obtained by maximum likelihood. However, simply estimating $\beta$ is of limited value, since we are not interested in $E\left(W T I^{*} \mid \mathbf{x}\right)=\mathbf{x}^{\prime} \beta$ as $W T I^{*}$ is just an abstract construct. Instead, we are interested in assessing the response probabilities, i.e. the impacts of the explanatory variables on WTI. This information can be extracted from calculating the marginal effects, i.e. the effects that a change in the explanatory variables has on the cell probabilities. These effects can be written as:

$$
\partial \operatorname{Pr}[\operatorname{cell} j] / \partial x_{i}=\beta\left[\begin{array}{ll}
\lambda & \delta_{j-1}-\beta^{\prime} x_{i}-\lambda \delta_{j}-\beta^{\prime} x_{i}
\end{array}\right]
$$

where $\lambda(\cdot)$ is the standard logistic density. Since the marginal effects vary with the levels of the explanatory variables, they are calculated at the mean values of $\mathbf{x}$. While for continuous variables such marginal effects can be interpreted as elasticities, for dummy variables they represent changes in the predicted probabilities for unit changes from a status of 0 to a status of 1 .

As before, we include a set of control variables and a set of additional variables capturing aspects of technological and organizational change. Moreover, in the ordered logit estimates on training composition, as well as in the estimates on training intensity, we define five new variables which measure, respectively, the intensity of recruitment at time $t-1$, the intensity of investments in new equipment, the intensity of innovation activity, the intensity of internationalization commitment and the intensity of outsourcing.

The intensity of recruitment is given by the log share of new entrants in year 2003 (Log_hire2003). The intensity of investments in new machines and equipment is measured, instead, as the (natural log) of average 2001-2003 investments per employee deflated by a 2001-based business investments price index ( $\log _{-}$inv).

As regard techno-organizational change, we first build an index of innovation intensity (inno_comb) that equals 0 for non innovative firms $(32.04 \%), 1$ for firms that introduced a new product in the period 2001-2003 (19.81\%), 2 for firms that introduced a new product and a new process $(29.26 \%)$, and 3 for firms that, after product and process innovations, also introduced new organizational practices $(18.90 \%)$.

Secondly, we define a foreign expansion index $(F E I)$, as developed in Basile et al. (2003), in order to measure the degree of internationalization of the firm This index integrates various dimensions of commitment to internationalization: exports, production 
offshoring and the purchase of services from abroad ${ }^{20}$. Thus, the $F E I$ ranges in value from 0 to 3: 0 for firms not involved in any international trade activity $(28.03 \%), 1$ for the firms that only export goods and services $(52.36 \%) ; 2$ for firms exporting and purchasing knowledge-intensive services from abroad $(15.99 \%) ; 3$ for firms exporting, purchasing services and offshoring production abroad ( $3.62 \%)$.

Finally, we measure outsourcing intensity by defining an index (out_int) that takes the value of 0 for firms developing all the phases of their production process internally (77.99\%), 1 for firms outsourcing one phase $(13.92 \%), 2$ for firms outsourcing two phases (3.62\%) and 3 for firms outsourcing more than 2 phases $(4.47 \%)$.

\subsection{Estimates on training intensity}

Finally, we estimate training intensity by relying on both real training costs per employee (in natural $\operatorname{logs}$ ) and the (natural $\log$ ) number of trainees over the total number of employees in 2004 (Log_trainees). With respect to the former, in particular, we explicitly distinguish between real total training costs $\left(\log _{-} T T C\right)$ and real private training costs $\left(\log _{-} T P C\right)^{21}$.

Since we observe our dependent variables only for firms providing training in 2004, it is possible that firms with positive expenditure levels or positive shares of trainees are not randomly selected from the population, so that a sample selection may arise that biases standard OLS estimates.

In order to avoid such a problem, we employ a Heckman two-step selection model (Heckman, 1979). On this purpose, we first define $T C^{*}$ as our outcome of interest, i.e. training expenditures in $2004^{22}$. This outcome is observed only if $T C^{*}>0$. We then introduce a latent variable, $W B T^{*}$ (work-based training) so that is observed only if $W B T^{*}>0$, that is, only when firms do invest in training activities. Assuming a linear specification of the model, we obtain the following system of two equations:

$$
\begin{aligned}
& W B T^{*}=\mathbf{x}_{1}^{\prime} \beta_{1}+\varepsilon_{1} \\
& T C^{*}=\mathbf{x}_{2} \beta_{2}+\varepsilon_{2}
\end{aligned}
$$

with $\varepsilon_{1}$ and $\varepsilon_{2}$ jointly normally distributed and homoskedastic.

The two-step method is based on the conditional expectation:

$$
E\left(T C \mid \mathbf{x}, W B T^{*}>0\right)=\mathbf{x}_{2}^{\prime} \beta_{2}+\sigma_{12} \lambda\left(\mathbf{x}_{1}^{\prime} \beta_{1}\right)
$$

\footnotetext{
${ }^{20}$ Services include transport, insurance, communication, financing, informatics, R\&D and design.

${ }^{21}$ Both total and private training costs are divided by 2001-based GDP deflator.

${ }^{22}$ The same approach is valid also for the share of trainees.
} 
in which $\lambda\left(\mathbf{x}_{1}^{\prime} \beta_{1}\right)$ is the so called inverse Mills ratio and $\sigma_{12}$ is the covariance between $\varepsilon_{1}$ and $\varepsilon_{2}$, and where $\beta_{1}$ is obtained by probit regression of $W B T$ on $\mathbf{x}_{1}$, and the second step OLS regression of $T C$ on $\mathbf{x}_{2}$ leads to a semi-parametric estimate of $\left(\beta_{2}, \sigma_{12}\right)$.

Therefore, we proceed in the following way: we first estimate a probit model on the propensity to train in year 2004, and then we include such a probability into the OLS second-stage estimation of training costs (and training share) in order to obtain consistent estimates of the parameters of interest.

As explanatory variables, we include firm employment size, skill intensity, capital intensity, the share of previously recruited personnel, the previous use of public funds for financing training, investments in new machinery per employee, innovation intensity, the degree of engagement in foreign market penetration and the intensity of outsourcing.

\section{Main results}

Tables from 12 to 14 show the results from the logit estimates on the propensity to invest in WBT in 2004, for WBT by occupation (managers and plant operators) and typology of training respectively.

Concerning the former, we present three different specifications of the model. In the first (Model 1), after controlling for geographical location and industrial specialization, we focus on technological innovations, as the capacity of the firm to introduce new products and/or new processes in the three years before training. In the second specification (Model 2), instead, we focus on techno-organizational innovation, as the capacity of the firm to re-organize its production process after the introduction of a technological innovation. Finally, in the third specification (Model 3) we consider the two variables together.

As the estimates show, the choice to invest in WBT positively depends on: firm size (increasing the labour-force by $1 \%$ leads to an increase in the probability to train by $15 \%)$, skill intensity $(9 \%)$, use of private funds for financing training $(24 \%)$, investments in new machinery (11\%), techno-organizational change $(7 \%)$, and, more weakly, the purchase of services from abroad $(8 \%)$ and the outsourcing of production phases to external suppliers (7\%).

Interestingly, the use of public funds does not seem to stimulate training propensity, as well as neither engagement in exporting activities nor offshoring. The previous recruitment of new personnel does have a positive impact, but not significantly different from zero.

As regard organizational change, we note that only the adoption of new organizational practices after the previous introduction of technological innovations does play an impact on WBT. Since our variable captures the joint occurrence of technological and 
organizational change, we speculate that technology does stimulate training only when it is followed by an organizational change. Therefore, technological and organizational change may be considered as complementary inputs in the training decision of manufacturing firms.

Table 12 Propensity to train 2004: logit estimates

\begin{tabular}{|c|c|c|c|}
\hline Dep. var. WBT & Model 1 & Model 2 & Model 3 \\
\hline Log_employees & $0.150(0.017)^{* * *}$ & $0.150(0.017)^{* * * *}$ & $0.187(0.017)^{* * *}$ \\
\hline $\log (\mathrm{WC} / \mathrm{L})$ & $0.089(0.029)^{* *}$ & $0.087(0.029)^{* *}$ & $0.105(0.029)^{* *}$ \\
\hline $\log (\mathrm{K} / \mathrm{L})$ & $0.013(0.019)$ & $0.012(0.019)$ & $0.013(0.018)$ \\
\hline hire 2003 & $0.031(0.039)$ & $0.026(0.039)$ & $0.033(0.038)$ \\
\hline private & $0.235(0.033)^{* * *}$ & $0.235(0.033)^{* * * *}$ & \\
\hline public & & & $0.048(0.044)$ \\
\hline investment & $0.114(0.059)^{*}$ & $0.110(0.060)^{*}$ & $0.126(0.058)^{* *}$ \\
\hline inno_tech & $0.024(0.036)$ & $-0.008(0.039)$ & $0.003(0.038)$ \\
\hline inno_org & & $0.073(0.036)^{* *}$ & $0.069(0.035)^{* *}$ \\
\hline export & $-0.074(0.046)$ & $-0.072(0.046)$ & $-0.062(0.045)$ \\
\hline offshoring & $-0.030(0.051)$ & $-0.034(0.052)$ & $-0.033(0.049)$ \\
\hline services & $0.082(0.039)^{* *}$ & $0.083(0.039)^{* *}$ & $0.083(0.038)^{* *}$ \\
\hline outsourcing & $0.063(0.040)$ & $0.060(0.040)$ & $0.071(0.039)^{*}$ \\
\hline Area dummies & Yes & Yes & Yes \\
\hline Industry dummies & Yes & Yes & Yes \\
\hline N. Obs. & 1410 & 1410 & 1410 \\
\hline Pseudo $\mathrm{R}^{2}$ & 0.2065 & 0.2087 & 0.1842 \\
\hline $\begin{array}{l}\text { H-L Gof test } \chi^{2} \\
(1382)\end{array}$ & $1383.56(0.4831)$ & $1383.33(0.4773)$ & $1391.42(0.4166)$ \\
\hline LogPseudolikelihood & -774.78982 & -772.64293 & -796.56206 \\
\hline
\end{tabular}

Notes: the estimate of the coefficients refers to marginal effects at the sample mean. Heteroskedasticconsistent standard errors in brackets. $(*)$ significant at $10 \% ;(* *)$ significant at $5 \% ;(* * *)$ significant at $1 \%$. Intercept coefficients are not reported. Hosmer-Lemeshow goodness of fit test does not reject the null hypothesis of correct specification of the models ( $p$-values in brackets).

When looking at international trade activities, only the acquisition of services from abroad seems to have a positive effect on WBT. The acquisition of knowledge-intensive business services, - like financial services, insurance, transport, R\&D, design and so on for instance, may require firms to develop the necessary skills in order to operate them.

Finally, when dealing with market-oriented activities, the outsourcing of ancillary production and service activities, may allow firms to specialize on the high-skill intensive phases of their value chain, thus stimulating them to invest more intensively in skill formation through WBT.

When we split the dependent variable by occupation, we find some interesting results, as shown in Table 13. First of all, the impact of firm size seems to be higher when firms 
train managers with respect to plant operators. One possible explanation is that managers working in large firms, other than processing a wider set of activities than managers working in smaller firms, have also to deal more intensively with activities like supervision, control, process design and work recruitment, that require a continuous upgrading of their skills.

As expected, skill intensity is important only when referring to the choice to train managers, whereas capital intensity is important when dealing with the decision to train plant operators, this latter piece of evidence confirming the complementary between physical and human capital at the workplace.

As before, the use of private funds increases both the propensity to train managers and the propensity to train plant operators, the former being particularly more affected $(+25 \%)$. On the contrary, the use of public funds in 2003 does not have any significant effect.

Techno-organizational change, instead, seems to stimulate more the propensity to train plant operators $(8 \%)$ rather than managers $(6 \%)$, while the purchase of knowledgeintensive services and outsourcing seem to be relevant only when a more general propensity to train (managers, executives and operators) is considered.

A look at the determinants of WBT by typology of training add the previous picture some more information. As clearly emerges from Table 4.14, in-house training seems to be more chosen when high skills are available $(+6 \%)$, when the firm previously utilized private funds for financing training activities $(+18 \%)$, when techno-organizational innovation occurs $(+6 \%)$, when the firm purchases knowledge intensive business services from abroad $(+9 \%)$ and when the firm contracts out phases of the production process tat were previously developed internally $(+8 \%)$.

A slightly different picture seems, instead, to characterize the choice to provide training outside the firm. In this case, skills availability seems to gain importance $(+8 \%)$ as well as techno-organizational change $(+7 \%)$ and previous investments in capitalembodied technology $(+15 \%)$. The arrivals of new machines as well as the introduction of new organizational practices, thus, play the most significant role in driving the firm decision to invest in external courses. 
Table 13 Propensity to train by occupation 2004: logit estimates

\begin{tabular}{|c|c|c|c|c|}
\hline & $\begin{array}{l}\text { WBTM } \\
\text { (1) }\end{array}$ & $\begin{array}{c}\text { WBTM } \\
\text { (2) }\end{array}$ & $\begin{array}{c}\text { WBTO } \\
\text { (1) }\end{array}$ & $\begin{array}{c}\text { WBTO } \\
\text { (2) }\end{array}$ \\
\hline Log_employees & $0.176(0.018)^{* * *}$ & $0.216(0.018)^{* * *}$ & $0.137(0.016)^{* * *}$ & $0.170(0.016)^{* * *}$ \\
\hline $\log (\mathrm{WC} / \mathrm{L})$ & $0.117(0.030)^{* * *}$ & $0.134(0.030)^{* * *}$ & $-0.002(0.025)$ & $0.015(0.026)$ \\
\hline $\log (\mathrm{K} / \mathrm{L})$ & $-0.008(0.019)$ & $-0.006(0.019)$ & $0.049(0.018)^{* *}$ & $0.048(0.017)^{* *}$ \\
\hline hire 2003 & $0.027(0.040)$ & $0.035(0.038)$ & $0.018(0.036)$ & $0.024(0.034)$ \\
\hline private & $0.250(0.033)^{* * *}$ & & $0.168(0.032)^{* * *}$ & \\
\hline public & & $0.053(0.044)$ & & $-0.004(0.038)$ \\
\hline investment & $0.102(0.060)^{*}$ & $0.118(0.057)^{* *}$ & $0.082(0.056)$ & $0.093(0.055)^{*}$ \\
\hline inno_tech & $-0.010(0.040)$ & $-0.002(0.039)$ & $0.016(0.036)$ & $0.021(0.035)$ \\
\hline inno_org & $0.063(0.036)^{*}$ & $0.058(0.036)$ & $0.080(0.033)^{* *}$ & $0.078(0.033)^{* *}$ \\
\hline export & $-0.043(0.049)$ & $-0.032(0.048)$ & $-0.051(0.044)$ & $-0.043(0.044)$ \\
\hline offshoring & $-0.017(0.053)$ & $-0.017(0.050)$ & $0.001(0.045)$ & $0.003(0.044)$ \\
\hline services & $0.057(0.039)$ & $0.059(0.039)$ & $0.029(0.036)$ & $0.032(0.035)$ \\
\hline outsourcing & $0.058(0.041)$ & $0.070(0.039)^{*}$ & $0.030(0.036)$ & $0.039(0.036)$ \\
\hline Area dummies & Yes & Yes & Yes & Yes \\
\hline Industry dummies & Yes & Yes & Yes & Yes \\
\hline N. Obs. & 1410 & 1410 & 1410 & 1410 \\
\hline Pseudo $\mathrm{R}^{2}$ & 0.2450 & 0.2172 & 0.1834 & 0.1687 \\
\hline \multirow[t]{2}{*}{ H-L Gof test $\chi^{2}$} & 1379.84 & 1391.95 & 1416.15 & 1422.52 \\
\hline & $(0.5037)$ & $(0.4128)$ & $(0.2496)$ & $(0.2133)$ \\
\hline LogPseudolikelihood & -731.03972 & -757.91239 & -768.21212 & -782.0354 \\
\hline
\end{tabular}

Notes: the estimate of the coefficients refers to marginal effects at the sample mean. Heteroskedasticconsistent standard errors in brackets. $(*)$ significant at $10 \% ;(* *)$ significant at $5 \% ;(* * *)$ significant at $1 \%$. Intercept coefficients are not reported. Hosmer-Lemeshow goodness of fit test does not reject the null hypothesis of correct specification of the models ( $p$-values in brackets).

Finally, training through coaching seems to be stimulated mainly by the previous recruitment of workers and by previous private spending, even if in this latter case the impact is lower than for in-house and outside training. In this respect, coaching can be thought as a particularly useful form of training when the firm, after hiring new personnel, needs to make such new workers rapidly adapt to the technology and the organization of production, i.e. to the working environment. Put it another way, while more formal typologies of training seem to be linked to complex activities, like technoorganizational innovations or international trade, coaching ca be considered as the first tool through which newly hired workers approach the firm and its organization. 
Table 14. Propensity to provide in-house, outside and coaching training

\begin{tabular}{|c|c|c|c|c|c|}
\hline & $\begin{array}{l}\text { WBT in- } \\
\text { house }\end{array}$ & $\begin{array}{c}\text { WBT in- } \\
\text { house }\end{array}$ & $\begin{array}{c}\text { WBT } \\
\text { outside }\end{array}$ & $\begin{array}{c}\text { WBT } \\
\text { outside }\end{array}$ & $\begin{array}{c}\text { WBT } \\
\text { coaching }\end{array}$ \\
\hline Log_employees & $\begin{array}{c}0.197 \\
(0.017)^{* * *}\end{array}$ & $\begin{array}{c}0.226 \\
(0.017)^{* * * *}\end{array}$ & $\begin{array}{c}0.127 \\
(0.016)^{* * *}\end{array}$ & $\begin{array}{c}0.164 \\
(0.016)^{* * *}\end{array}$ & $\begin{array}{c}0.195 \\
(0.015)^{* * *}\end{array}$ \\
\hline $\log (\mathrm{WC} / \mathrm{L})$ & $0.064_{* * *}(0.027)$ & $0.077_{* * *}^{(0.027)}$ & $\begin{array}{c}0.081 \\
(0.027)^{* *}\end{array}$ & $\begin{array}{c}0.098 \\
(0.027)^{* *}\end{array}$ & $\begin{array}{c}0.019 \\
(0.022)\end{array}$ \\
\hline $\log (\mathrm{K} / \mathrm{L})$ & $0.008(0.018)$ & $0.009(0.018)$ & $0.007(0.018)$ & $0.007(0.018)$ & $\begin{array}{c}0.019 \\
(0.015)\end{array}$ \\
\hline hire 2003 & $\begin{array}{l}-0.012 \\
(0.038)\end{array}$ & $\begin{array}{l}-0.006 \\
(0.037)\end{array}$ & $0.013(0.035)$ & $0.020(0.035)$ & $\begin{array}{c}0.088 \\
(0.025)^{* * *}\end{array}$ \\
\hline private & $\begin{array}{c}0.179 \\
(0.033)^{* * *}\end{array}$ & & $\begin{array}{c}0.180 \\
(0.031)^{* * *}\end{array}$ & & $\begin{array}{c}0.107 \\
(0.026)^{* * *}\end{array}$ \\
\hline public & & $0.044(0.041)$ & & $\begin{array}{l}-0.015 \\
(0.037)\end{array}$ & \\
\hline investment & $0.060(0.058)$ & $0.074(0.058)$ & $\begin{array}{c}0.151 \\
(0.050)^{* *}\end{array}$ & $\begin{array}{c}0.158 \\
(0.048)^{* *}\end{array}$ & $\begin{array}{l}-0.075 \\
(0.062)\end{array}$ \\
\hline inno_tech & $\begin{array}{l}-0.009 \\
(0.038)\end{array}$ & $\begin{array}{l}-0.001 \\
(0.037)\end{array}$ & $\begin{array}{l}-0.032 \\
(0.036)\end{array}$ & $\begin{array}{l}-0.023 \\
(0.035)\end{array}$ & $\begin{array}{c}0.020 \\
(0.029)\end{array}$ \\
\hline inno_org & $\begin{array}{c}0.057 \\
(0.034)^{*}\end{array}$ & $0.053(0.034)$ & $\begin{array}{c}0.065 \\
(0.033)^{* *}\end{array}$ & $\begin{array}{c}0.063 \\
(0.032)^{*}\end{array}$ & $\begin{array}{c}0.018 \\
(0.030)\end{array}$ \\
\hline export & $\begin{array}{l}-0.070 \\
(0.048)\end{array}$ & $\begin{array}{l}-0.063 \\
(0.048)\end{array}$ & $\begin{array}{l}-0.041 \\
(0.045)\end{array}$ & $\begin{array}{l}-0.030 \\
(0.045)\end{array}$ & $\begin{array}{l}-0.020 \\
(0.039)\end{array}$ \\
\hline offshoring & $\begin{array}{l}-0.044 \\
(0.044)\end{array}$ & $\begin{array}{l}-0.043 \\
(0.044)\end{array}$ & $0.018(0.047)$ & $0.020(0.046)$ & $\begin{array}{l}-0.065 \\
(0.031)^{* *}\end{array}$ \\
\hline services & $\begin{array}{c}0.086 \\
(0.038)^{* *}\end{array}$ & $\begin{array}{c}0.088 \\
(0.038)^{* *}\end{array}$ & $0.037(0.035)$ & $0.039(0.034)$ & $\begin{array}{c}0.014 \\
(0.030)\end{array}$ \\
\hline outsourcing & $\begin{array}{c}0.074 \\
(0.040)^{*}\end{array}$ & $\begin{array}{c}0.083 \\
(0.039)^{* *}\end{array}$ & $0.031(0.035)$ & $0.042(0.035)$ & $\begin{array}{l}-0.019 \\
(0.029)\end{array}$ \\
\hline Area & Yes & Yes & Yes & Yes & Yes \\
\hline Industry & Yes & Yes & Yes & Yes & Yes \\
\hline N. Obs. & 1410 & 1410 & 1410 & 1410 & 1410 \\
\hline Pseudo $\mathrm{R}^{2}$ & 0.2524 & 0.2370 & 0.1964 & 0.1787 & 0.2793 \\
\hline H-L Gof test & $\begin{array}{l}1371.56 \\
(0.5664)\end{array}$ & $\begin{array}{l}1378.07 \\
(0.5172)\end{array}$ & $\begin{array}{l}1389.98 \\
(0.4273)\end{array}$ & $\begin{array}{l}1404.28 \\
(0.3252)\end{array}$ & $\begin{array}{l}1450.49 \\
(0.100)\end{array}$ \\
\hline LogPseudo-like & -701.54837 & -716.00523 & -743.69391 & -760.14362 & -615.76708 \\
\hline
\end{tabular}

The ordered logit estimates, instead, aim at identifying to what extent the variables previously identified do affect the composition - or the heterogeneity - of WBT, as assumed to be a proxy of firm-specific human capital. 
Table 15 reports the estimated coefficients of the significant variables in the ordered logit regressions. Interestingly, firm size, the share of high-skilled personnel, capitalembodied technological change (i.e. capital intensity and investments in new equipment), organizational innovation due to the introduction of new processes are still the most significant drivers of WTI, while the recruitment of new personnel and foreign expansion activities are now not significant. Estimates based on Model 3 also show that the index of innovation intensity is significant $(p<0.05)$. The more heterogeneous the set of innovation activities in which the firm is engaged, the more heterogeneous seems to be the training portfolio implemented.

Table 15. Training index 2004: ordered logit estimates

\begin{tabular}{lc}
\hline \hline & Model 1 \\
\hline Log_employees & $1.021(0.095)^{* * *}$ \\
Log $(\mathrm{WC} / \mathrm{L})$ & $0.403(0.152)^{* *}$ \\
Log $(\mathrm{K} / \mathrm{L})$ & $-0.008(0.105)$ \\
private & $0.799(0.162)^{* * *}$ \\
Log_hire 2003 & $0.035(0.086)$ \\
Log_inv & $-0.013(0.064)$ \\
inno_comb & $0.185(0.073)^{* *}$ \\
FEI & $-0.096(0.106)$ \\
out_int & $0.167(0.087)^{*}$ \\
Area dummies & Yes \\
Industry dummies & Yes \\
N. Obs. & 882 \\
Pseudo R & 0.1814 \\
Log Likelihood & -786.23683 \\
Cut point $\delta_{1}$ & $5.422(1.165)$ \\
Cut point $\delta_{2}$ & $6.207(1.170)$ \\
Cut point $\delta_{3}$ & $7.058(1.176)$ \\
LR test for proportional odds $\chi^{2}(50)$ & $54.04(p-v a l u e 0.3227)$ \\
\hline Notes: Heteroskedasticity-robust standard errors. $(*)$ significant at \\
$10 \% ;(* *)$ significant at $5 \% ;(* * *)$ significant at $1 \%$. LR test confirms \\
that the hypothesis of proportional odds is not violated.
\end{tabular}

However, as stated before, the information contained in Table 15 is relevant just for suggesting the variables that are important in explaining individual heterogeneity in WTI among firms. Table 16, instead, reports the marginal effects of such variables on the three categories in which $W T I>0$.

What clearly emerges is that the marginal impact of each variable on WTI increases when passing from one category to the following one. For our purpose this means that, apart from previous private spending, skill, innovation and -more weakly - outsourcing 
intensity are drivers of training intensity. In particular, adding organizational change to technological innovations requires the firm to activate all the three typologies of training, even if this impact is not particularly strong (about 1.6). Interestingly, training intensity and complexity is also increasingly driven by the utilization of private funds, while public funds do not have any impact.

Table 16. Marginal effects on the index of training composition 2004

\begin{tabular}{lccc}
\hline Variables & $\operatorname{Pr}(\mathbf{W T I}=1)$ & $\operatorname{Pr}(\mathbf{W T I}=2)$ & $\operatorname{Pr}(\mathbf{W T I}=3)$ \\
\hline Size & $0.066(0.010)^{* * * *}$ & $0.077(0.011)^{* * *}$ & $0.097(0.011)^{* * *}$ \\
Log $(\mathrm{WC} / \mathrm{L})$ & $0.026(0.010)^{* *}$ & $0.030(0.012)^{* *}$ & $0.038(0.015)^{* * *}$ \\
private & $0.049(0.011)^{* * *}$ & $0.060(0.013)^{* * *}$ & $0.079(0.017)^{* * *}$ \\
inno_comb & $0.012(0.005)^{* *}$ & $0.014(0.006)^{* *}$ & $0.018(0.007)^{* *}$ \\
out_int & $0.011(0.006)^{*}$ & $0.013(0.007)^{*}$ & $0.016(0.008)^{*}$ \\
\hline
\end{tabular}

Finally, Table 17 presents the results of the Heckman selection models for unit training costs, both private $\left(\log \_T P C\right)$ and total $\left(\log _{-} T T C\right)$, and for the share of trainees (Log_trainees).

Table 17. Training intensity: Heckman two-step estimation

\begin{tabular}{lccc}
\hline & Log_TPC & Log_TTC & Log_trainees \\
\hline Log_employees & $0.302(0.179)^{*}$ & $0.260(0.170)$ & $0.372(0.168)^{* *}$ \\
Log (WC/L) & 0.603 & $0.580(0.156)^{* * *}$ & $0.516(0.152)^{* *}$ \\
& $(0.160)^{* * *}$ & & \\
Log (K/L) & $-0.013(0.086)$ & $0.013(0.082)$ & $-0.081(0.081)$ \\
Log_hire 2003 & $0.061(0.072)$ & $0.045(0.69)$ & $0.064(0.068)^{* *}$ \\
Log_inv & $0.080(0.064)$ & $0.057(0.062)$ & $0.130(0.060)^{*}$ \\
public & $0.151(0.185)$ & $0.246(0.178)$ & $0.171(0.177)$ \\
inno_comb & $0.159(0.065)^{* *}$ & $0.133(0.063)^{* *}$ & $0.119(0.063)^{*}$ \\
FEI & $-0.056(0.082)$ & $-0.079(0.078)$ & $-0.095(0.078)$ \\
out_int & $0.010(0.073)$ & $0.022(0.069)$ & $0.085(0.069)$ \\
Area dummies & Yes & Yes & Yes \\
Industry dummies & Yes & Yes & Yes \\
\hline N. Obs. & 911 & 914 & 914 \\
Censored Obs. & 452 & 452 & 452 \\
Uncensored Obs. & 459 & 462 & 462 \\
Mills lambda & $1.387(0.780)^{*}$ & $1.176(0.770)$ & $1.399(0.745)^{*}$ \\
\hline \multicolumn{2}{c}{ Notes: $(*)$ significant at $10 \% ;(* *)$ significant at $5 \% ;(* * *)$ significant at $1 \%}$.
\end{tabular}

Both training costs and the share of trainees are positively affected by firm dimension, skill intensity and innovation intensity. With respect to the latter, in particular, we find 
that adding organizational changes after the introduction of new product or process technologies increases the intensity of training by an amount between $12 \%$ (for trainees) and $16 \%$ (for costs). Investments in capital-embodies technology, instead, seem to affect only the relative number of trainees $(+13 \%)$.

Interestingly, previous spending of public funds does not have any influence on future training activity. The same is true for internationalization, outsourcing and the recruitment of new personnel in 2003.

Summing up, we find evidence that firms form and upgrade their workforce skills the more the production process is characterized by changes in its technological and organizational structure. However, while a relatively wide set of factors seem to affect the decision to train or not, few variables do also have an impact on the intensity of training. Once decided to train, the amount of training ${ }^{23}$ supplied depends on how intense is the process of techno-organizational change and on the stock of high-skilled personnel available.

\section{Conclusions}

In this paper we provide a first theoretical and empirical attempt to measure human capital from the labour demand perspective. From a theoretical point of view, we assume that a labour market characterized by job-competition can be a useful background in order to stress the importance of training as a type of firm-level activity devoted to the creation of new skills. In particular, we stress the concept of 'competence pipeline' as a useful theoretical tool for better describing how changes linked to the internal organization of knowledge lead to changes in the amount of specific human capital acquired by individuals on the job.

Relying on such framework of analysis, we merge three rich firm-level datasets and we estimate the impact of a set of variables that are supposed to affect both the propensity to invest in WBT and the intensity of training within the Italian manufacturing industry over the period 2001-2005. In this respect, we devote special attention to technological and organizational innovation, international trade, the outsourcing of production activities, the use of private versus public funds for financing previous WBT and previous recruitment of new personnel.

Our estimates show that, when looking at the probability to invest in WBT programmes in general, innovation impacts more than international trade, and in particular when new technologies are followed by organizational innovations. When we disaggregate our dependent variable by occupation and by typology of training provided, we find that techno-organizational innovation, as well as capital-embodied technological change, seem to affect more the propensity to train plant operators than managers.

23 Unfortunately we do not have information on training hours. 
When looking at the type of WBT, we find that, apart from size and skill intensity, while outsourcing and the purchase of business services positively affect the propensity to provide in-house training, techno-organizational change seems to drive the choice to train outside the firm. A coaching-like training activity, instead, seems to be the first type of skill development strategy provided by firms as it is mainly affected by previous recruitment. Finally we estimate training intensity in terms, respectively, of the number of training activities provided, private and total training costs and the share of trainees. Our results point to a positive and significant effect of skill intensity and innovation intensity, while no significant effect is found for the degree of commitment to internationalization.

This paper can be considered as a first exploratory exercise towards a more detailed and robust analysis of human capital measurement conceived from the labour demand perspective. Our present aim is to investigate, theoretically and empirically, if and to what extent WBT can be considered a proxy of human capital. In addition to that, we analyse which factors contribute to explain the heterogeneity of WBT among manufacturing firms. As schooling, background characteristics, ability and age can measure human capital from the point of view of labour supply, firm's investments in new technology, in new organizational practices, in highly-skilled personnel and in international trade activities can be taken as important determinants of human capital from the point of view of the labour demand. 


\section{References}

Agarval R., Audretsch R.B. (2001), Does entry size matter? The impact of the life cycle and technology on firm survival, The Journal of Industrial Economics, vol. 1, pp. 2143.

Antonelli G. (2008), Principi economici di base nella valutazione dell'istruzione universitaria, in Cammelli A., Vittadini G. (eds.), Capitale umano: Esiti dell'istruzione universitaria, Bologna, Il Mulino.

Antonelli G. (2003) (a cura di), Istruzione, economia e istituzioni, Bologna, Il Mulino.

Antonelli G. and Pegoretti G. (2008), Knowledge endowment and composition as dynamic capabilities, in R. Leoncini and S. Montresor (eds.), Dynamic capabilities between firm organization and local systems of production, London, Routledge.

Antonietti R. (2007), Opening the 'skill-biased technological change' black box: a look at the microfoundations of the technology-skill relationship, Economia Politica, vol. XIV, n. 4, pp. 451-475.

Baldwin J.R. and Johnson J. (1995), Human capital development and innovation: the case of small and medium-sized firms, Statistics Canada Working Paper n. 74.

Baldwin J.R., Gray T. and Johnson J. (1995), Technology use, training and plant-specific knowledge in manufacturing establishments, Statistics Canada Working Paper n. 86.

Basile R., Giunta A. and Nugent J.B. (2003), Foreign expansion by Italian manufacturing firms in the Nineties: an ordered probit analysis, Review of Industrial Organization, vol. 23, pp. 1-24.

Bassanini A., Booth A., Brunello G., De Paola M. and Leuven E. (2007), Workplace training in Europe, in Brunello G., Garibaldi P. and Wasmer E. (eds.), Education and training in Europe, Oxford, Oxford University Press.

Becker G.S. (1964), Human capital, Columbia University Press, New York.

Blaug M. (1972), An introduction to the economics of education, Harmondsworth, Penguin Books.

Capitalia (2005), Indagine sulle imprese manifatturiere - IX rapporto, Osservatorio Piccole e Medie Imprese, Roma, Capitalia.

Centro Studi Unioncamere (2007), Rapporto Excelsior 2007, Roma, Unioncamere.

Coleman J.S. (1990), Foundations of Social Theory, Cambridge, MA, Belknap Press, p. 34.

European Commission (2004), Innovation in Europe (CIS3), Luxembourg, Office for Official Publications of the European Communities.

Fisher I. (1906), The Nature of Capital and Income, New York, MacMillan.

Folloni G, Vittadini G. (2009), Human Capital measurement. A survey,

Greene W.H. (2002), Econometric analysis, V edition, Prentice Hall.

Heckman J.J. (1979), Sample selection bias as a specification error, Econometrica, vol. 47, pp. 153-61. 
Heijke H. and Muysken J. (Eds.) (2000), Education and training in a knowledge-based economy, Palgrave.

Hollenstein H. and Stucki T. (2008), The impact of ICT usage, workplace organisation and human capital on the provision of apprenticeship training. A firm-level analysis based on Swiss panel data, KOF Working Paper n. 205, September.

ICE-ISTAT (2007), Commercio estero e attività internazionali delle imprese, Annuario ISTAT-ICE 2006, Roma.

ISTAT (2001), VIII Censimento dell'industria e dei servizi, Rome, ISTAT.

Le T., Gibson J. and Oxley L. (2006), Cost and income based measures of human capital, Journal of Economic Surveys, vol. 17, n. 3, pp. 271-307.

Lovaglio P. (2009), The estimation of Human Capital by administrative archives in a static and longitudinal perspective: the case of Milan,

OECD (2001), Employment outlook, Paris, OECD.

Psacharopoulos, G. (1987), Economics of education. Research and studies, New York, Pergamon Press.

Stroombergen A., Rose D. and Nana G. (2002), Review of the statistical measurement of human capital, mimeo, Statistics New Zeland, Wellington, November.

Thurow L.C. (1975), Generating inequality, London, The MacMillan Press.

Woessmann L. (2003), Specifying human capital, Journal of Economic Surveys, vol.17, n. 3, pp. 239-270.

Wooldridge J.M. (1999), Econometric analysis of cross section and panel data, MIT Press. 


\section{Appendix}

Table A1. Sample structure by industry

\begin{tabular}{lcc}
\hline Industry & N. & $\mathbf{~ \% ~}$ \\
\hline 15-Food products and beverages & 116 & 7.51 \\
17-Textile & 118 & 7.64 \\
18-Wearing apparel & 44 & 2.85 \\
19-Leather, luggage, shoes & 62 & 4.01 \\
20-Wood (except furniture) & 36 & 2.33 \\
21-Paper and paper products & 39 & 2.52 \\
22-Publishing, printing and recorded media & 38 & 2.46 \\
23-Coke, petroleum products and nuclear fuel & 9 & 0.58 \\
24-Chemicals and chemical products & 90 & 5.83 \\
25-Rubber and plastics & 83 & 5.37 \\
26-Non-metallic mineral products & 92 & 5.95 \\
27-Basic metals & 66 & 4.27 \\
28-Fabricated metal products (except machinery) & 182 & 11.78 \\
29-Machinery and equipment & 272 & 17.61 \\
30-Office, accounting and computer machinery & 5 & 0.32 \\
31-Electrical machinery and apparatus & 66 & 4.27 \\
32-Radio, TV and communication equipment & 34 & 2.20 \\
33-Industrial process control equipment & 36 & 2.33 \\
34-Motor vehicles, trailers and semi-trailers & 33 & 2.14 \\
35-Other transport equipment & 25 & 1.62 \\
36-Other manufacturing, funriture, etc. & 99 & 6.41 \\
Total & $\mathbf{1 . 5 4 5}$ & $\mathbf{1 0 0 . 0 0}$ \\
\hline
\end{tabular}


Table A2. Exporting firms distribution by firm size and macro-regions

\begin{tabular}{lcccccc}
\hline & \multicolumn{2}{c}{ Small } & \multicolumn{2}{c}{ Medium } & \multicolumn{2}{c}{ Large } \\
\hline \multirow{3}{*}{ World } & $\mathbf{2 0 0 0}$ & $\mathbf{2 0 0 5}$ & $\mathbf{2 0 0 0}$ & $\mathbf{2 0 0 5}$ & $\mathbf{2 0 0 0}$ & $\mathbf{2 0 0 5}$ \\
Europe & 20.2 & 18.9 & 27.0 & 27.6 & 41.5 & 43.3 \\
Italy* & 20.3 & 18.9 & 27.4 & 27.9 & 40.8 & 42.9 \\
\hline
\end{tabular}

*Manufacturing industry. Elaborations from ICE on ISTAT data. Source: ICE-ISTAT (2007), Tables 8.3 e 8.4. pp. 383-384.

Table A3. Value of exports (mln of Euros) by firm size, Italian manufacturing

\begin{tabular}{lcccccccc}
\hline & \multicolumn{2}{c}{2002} & \multicolumn{2}{c}{2003} & \multicolumn{2}{c}{$\mathbf{2 0 0 4}$} & \multicolumn{2}{c}{$\mathbf{2 0 0 5}$} \\
\hline Firm size & Value & \%* & Value & \%* & Value & \%* & Value & \%* \\
Small (S) & 52.226 & 19.8 & 51.159 & 19.8 & 53.168 & 19.1 & 55.056 & 18.9 \\
Medium & & & & & & & & \\
(M) & 70.826 & 26.9 & 71.459 & 27.6 & 76.758 & 27.5 & 80.357 & 27.6 \\
Large (L) & 112.415 & 42.5 & 109.854 & 42.4 & 121.515 & 43.6 & 126.038 & 43.3 \\
M + L & 183.241 & 69.4 & 181.313 & 70.0 & 198.273 & 71.2 & 206.395 & 71.0 \\
S+M+L & $\mathbf{2 3 5 . 4 6 7}$ & $\mathbf{8 9 . 2}$ & $\mathbf{2 3 2 . 4 7 2}$ & $\mathbf{8 9 . 8}$ & $\mathbf{2 5 1 . 4 4 1}$ & $\mathbf{9 0 . 2}$ & $\mathbf{2 6 1 . 4 5 1}$ & $\mathbf{8 9 . 9}$ \\
Total & $\mathbf{2 6 4 . 0 9 3}$ & 100.0 & $\mathbf{2 5 8 . 8 8 8}$ & 100.0 & $\mathbf{2 7 8 . 6 2 5}$ & 100.0 & $\mathbf{2 9 0 . 8 8 9}$ & 100.0 \\
\hline Sour
\end{tabular}

Source: our calculations on ICE-ISTAT (2007) data, Table 5.1.1 p. 323.

Notes: $(*)$ percentage on the total value of exports; $(* *)$ percentage on the total value of exports, and, in brackets, on $\mathrm{S}+\mathrm{M}+\mathrm{L}$. 
Table A4. Variables description

\section{Variable Description}

Area North West: Liguria, Lombardia, Piemonte, Valle d'Aosta

North East: Emilia-Romagna, Friuli Venezia-Giulia, Trentino Alto Adige, Veneto

Centre: Lazio, Marche, Toscana, Umbria

South: Abruzzo, Basilicata, Calabria, Campania, Molise, Puglia, Sardegna, Sicilia

Capital intensity Real net technical assets over total employees (natural log, average 20012003) $\left(\log _{-} K / L\right)$

Industry 14 industry dummies according to the ATECO 1991 classification (see Table A1): 15 - food products and beverages; $17+18$ - textile and clothing; 19 - leather; 20 - wood; $21+22$ - paper and printing; 23 - oil refining; 24 chemicals; 25 - rubber and plastics; 26 - non-metal minerals; $27+28$ - metals and metal products; 29 - non-electric machinery; $30+31+32+33$ - office equipment, electric machinery, medical apparels; $34+35$ - vehicles and other transportation; 36 - furniture and other manufacturing industries

Innovation - Capital-embodied technology: dummy $=1$ if the firm invested in new machines and equipment in 2001-2003 (investment); real investments in new machines and equipment (natural logs, average 2001-2003) (Log_inv)

- Technological innovation: dummy $=1$ if the firm introduced a product and/or a process innovation in 2001-2003 (inno_tech)

- Techno-organizational innovation: dummy $=1$ if the firm introduced new organizational practices after the introduction of a new product or a new process in 2001-2003 (inno_org)

- Innovation intensity: number of innovations (product, process, technoorganizational) introduced in 2001-2003 (inno_comb)

Internationalization - Dummy=1 if the firm exported goods in 2001-2003 (export)

- Dummy=1 if the firm moved production abroad in 2001-2003 (offshoring)

- Dummy $=1$ if the firm purchased business services from abroad in 20012003 (services)

- Foreign expansion index: 0 if the firm is purely domestic; 1 if the firm engaged only in export activity; 2 if the firm exported and purchased business services from abroad; 3 if the firm exported, purchased services and offshored production in 2001-2003 (FEI)

Outsourcing - Dummy $=1$ if the firm contracted out production or service activities in 2001-2003 (outsourcing)

- Number of phases outsourced in 2001-2003 (out_int) 
Previous - Dummy=1if the firm recruited new workers in 2003 (hire 2003)

recruitment - Share of newly recruited personnel in 2003 (natural log) (Log_hire 2003)

Previous training - Dummy=1 if the firm utilized own private funds for financing training in financing 2003 (private)

- Dummy=1 if the firm utilized public funds for financing training in 2003 (public)

Skill intensity Share of white collars, computed as entrepreneurs + managers + executives + clerks (natural log, average 2001-2003) ( $\left.\log _{-} W C / L\right)$

Size Number of employees (natural log, average 2001-2003) (Log_employee)

Training - Dummy=1 if the firm provided any form of employee training in 2004 $(W B T)$

- Dummy $=1$ if the firm trained managers and executives in 2004 (WBTM)

- Dummy $=1$ if the firm trained plant operators in 2004 (WBTO)

- Dummy $=1$ if the firm provided in-house training in 2004 (WBT in-house)

- Dummy $=1$ if the firm provided outside training in 2004 (WBT outside)

- Dummy $=1$ if the firm provided coaching in 2004 (WBT coaching)

- Number of training typologies provided: in-house, outside, coaching (WTI)

- Real private training costs per employee in 2004 (natural log) (Log_TPC)

- Real total training costs per employee in 2004 (natural log) (Log_TTC)

- Share of trainees in 2004 (natural log) (Log_trainees)

Table A 5. Summary statistics

\begin{tabular}{rccccc}
\hline Variable & N. Obs. & Mean & St. Dev. & Min. & Max. \\
\hline K/L & 1420 & 49109.35 & 59044.12 & 468.1653 & 823142.8 \\
Log_K/L & 1420 & 10.36854 & 0.965061 & 6.148821 & 13.62088 \\
investments & 1545 & 0.9184466 & 0.2737717 & 0 & 1 \\
inv & 1313 & 9174.854 & 48132.33 & 0 & 1526533 \\
Log_inv & 1305 & 0.25624 & 1.341365 & 2.057011 & 14.23851 \\
inno_tech & 1545 & 6491909 & 0.4773778 & 0 & 1 \\
inno_org & 1545 & 0.3799353 & 0.4773778 & 0 & 1 \\
inno_comb & 1545 & 1.350162 & 1.116748 & 0 & 3 \\
export & 1545 & 0.8213592 & 0.3831753 & 0 & 1
\end{tabular}




\begin{tabular}{|c|c|c|c|c|c|}
\hline offshoring & 1545 & 0.1067961 & 0.3089539 & 0 & 1 \\
\hline services & 1545 & 0.2194175 & 0.413986 & 0 & 1 \\
\hline FEI & 1545 & 0.9521036 & 0.7636731 & 0 & 3 \\
\hline outsourcing & 1545 & 0.2200647 & 0.4144242 & 0 & 1 \\
\hline out_int & 1545 & 0.3456311 & 0.7529876 & 0 & 3 \\
\hline hire 2003 & 1545 & 0.7339806 & 0.4420176 & 0 & 1 \\
\hline Share_hire 2003 & 1545 & 0.0728697 & 0.1357882 & 0 & 2.955882 \\
\hline Log_hire 2003 & 1134 & -2.742356 & 0.9197016 & -5.929589 & 1.083797 \\
\hline private & 1545 & 0.4122977 & 0.4924076 & 0 & 1 \\
\hline public & 1545 & 0.192233 & 0.3941828 & 0 & 1 \\
\hline $\mathrm{WC} / \mathrm{L}$ & 1545 & 0.3211286 & 0.1854772 & 0 & 1.094254 \\
\hline Log_WC/L & 1534 & -1.28972 & 0.5932657 & -4.502769 & 0.0900732 \\
\hline employee & 1545 & 283.0928 & 623.946 & 6 & 12279.67 \\
\hline Log_employee & 1545 & 4.837768 & 1.206295 & 1.791759 & 9.4157 \\
\hline WBT & 1545 & 0.4802589 & 0.4997719 & 0 & 1 \\
\hline WBTM & 1545 & 0.4433657 & 0.4969431 & 0 & 1 \\
\hline WBTO & 1545 & 0.3825243 & 0.4861609 & 0 & 1 \\
\hline WBT in-house & 1545 & 0.3825243 & 0.4861609 & 0 & 1 \\
\hline WBT outside & 1545 & 0.361165 & 0.4804938 & 0 & 1 \\
\hline WBT coaching & 1545 & 0.2925566 & 0.4550838 & 0 & 1 \\
\hline WTI & 1545 & 0.8122977 & 1.159989 & 0 & 3 \\
\hline ТPC & 732 & 198.504 & 245.2091 & 2.841137 & 3518.898 \\
\hline Log_TPC & 732 & 4.740924 & 1.126336 & 1.044204 & 8.165903 \\
\hline TTC & 742 & 213.0186 & 256.9083 & 2.841137 & 3518.898 \\
\hline Log_TTC & 742 & 4.809586 & 1.132893 & 1.044204 & 8.165903 \\
\hline Trainee 2004 & 1545 & 0.1632633 & 0.2592984 & 0 & 1 \\
\hline Log_trainee & 742 & -1.525096 & 1.06815 & -5.287004 & 0 \\
\hline
\end{tabular}

